\title{
First Year Results of Suprachoroidal Adipose Tissue Derived Mesenchymal Stem Cell Implantation in Degenerative Macular Diseases
}

\author{
Neslihan Sinim Kahraman ${ }^{1}$, Zeynep Burcin Gonen ${ }^{2}$, Duygu Gulmez Sevim³, Ayse Oner ${ }^{1}$ \\ ${ }^{1}$ Ophthalmology Department, Kayseri Acibadem Hospital, Kayseri, Turkey \\ ${ }^{2}$ Genome and Stem Cell Center, Kayseri, Turkey \\ ${ }^{3}$ Ophthalmology Department, Erciyes University, Kayseri, Turkey
}

Background and Objectives: This study shows the clinical data of 1-year follow-up of 8 patients with degenerative macular diseases who received suprachoroidal adipose tissue derived mesenchymal stem cell (ADMSC) implantation. Methods and Results: This prospective, single-center, phase $1 / 2$ study enrolled 8 eyes of 8 patients with degenerative macular diseases of various reasons who underwent suprachoroidal implantation of ADMSCs. All patients had severe visual field defects and severe visual loss. All patients had defective multifocal electroretinography (mf ERG). The worse eye of the patient was selected for the operation. Patients were evaluated on the first day, first month, sixth month and at 1 year postoperatively. Best corrected visual acuity (BCVA), anterior segment and fundus examination, color photography, optical coherence tomography (OCT) and visual field (VF) examination were carried out at each visit. Fundus fluorescein angiography (FFA) and mfERG recordings were performed at the end of the sixth months. All 8 patients completed the 1 year follow-up. None of them had any systemic or ocular complications. Seven of the patients experienced visual acuity improvement, visual field improvement and improvement in the mfERG recordings. We found choroidal thickening in OCT of the four treated eyes.

Conclusions: Even though the sample size is small, stem cell treatment with suprachoroidal implantation of ADMSCs seems to be safe and the improvements were encouraging. To optimize the cell delivery technique and to evaluate the effects of this therapy on visual acuity and the quality of life of these patients, future studies with larger number of cases will be necessary.

Keywords: Adipose tissue, Mesenchymal stem cell, Macular diseases, Suprachoroidal implantation

Received: February 3, 2020, Revised: July 22, 2020,

Accepted: September 9, 2020, Published online: October 31, 2020

Correspondence to Ayse Oner

Ophthalmology Department, Kayseri Acibadem Hospital, Seyitgazi, Mustafa Kemal Paşa Blv. No:1, Kayseri 38030, Turkey

Tel: +90-530-2831611, Fax: +90-352-2074444

E-mail: ayseozoner@gmail.com

(a) This is an open-access article distributed under the terms of the Creative Commons Attribution Non-Commercial License (http://creativecommons.org/ licenses/by-nc/4.0/), which permits unrestricted non-commercial use, distribution, and reproduction in any medium, provided the original work is properly cited.

Copyright (C) 2021 by the Korean Society for Stem Cell Research

\section{Introduction}

Non-retinal-derived stem cells including embryonic stem cells (ESCs), induced pluripotent stem cells (IPSCs) and mesenchymal stem cells (MSCs) are currently being investigated extensively for the treatment of degenerative retinal diseases. Developmentally mature organs, such as bone marrow, adipose tissue, umblical cord and dental pulp are the most commonly used sources of MSCs. These stem cells show anti-apoptotic, anti-inflammatory, immunomodulatory and angiogenic effects through secretion of various cytokines, growth factors and proteins. MSCs 
also provide trophic support for the neuroprotection and regeneration of damaged retinal cells either directly through the secretion of neurotrophic factors (NTFs) or indirectly with the paracrine support (1-3).

Compared to bone marrow derived MSCs (BMMSCs), adipose tissue derived MSCs (ADMSCs) have the advantages of easier harvest from donors, faster expansion, more protein secretion and higher immunomodulatory capacity. Besides, ADMSCs express NTFs and vascular endothelial growth factor (VEGF) higher than BMMSCs. These data suggest that ADMSC may have therapeutic potential for neurodegenerative conditions through NTF production (46).

Dry type age-related macular degeneration (AMD), Stargardt's macular dystrophy (SMD) are common encountered degenerative macular diseases causing vision loss. Dry type AMD is one of the leading causes of vision loss in the elderly population in developed countries. Its main symptom is progressive and irreversible loss of central vision (7). SMD is the most common inherited macular dystrophy in both adults and children with a prevalence of 1 in 8,000 10,000. It mainly affects young people, often starting in late teens or early 20s. Patients present with bilateral central visual loss, including dyschromatopsia and central scotomata, with characteristic macular atrophy and yellow-white flecks at the level of the retina pigment epithelium (RPE), at the posterior pole (8).

Although there is no curative treatment for these diseases up to date, new approaches including restoring defective genes and stem cell transplantation to replace defective or dead cells have been under investigation (1-3). Finding an effective and safe treatment would help the patients' mental health and quality of life (QOL) affected by visual deterioration and may reduce the economic burden on the patients and society.

So the researchers mostly focus on these diseases which haven't got any curative treatment modality in order to evaluate the efficacy of stem cell therapy. There are currently many ongoing clinical trials which aim to test the safety and efficacy of stem cell transplantation in the eye.

Here we aim to report the medium term -1 year- results of patients with advanced stage retinal diseases who received suprachoroidal ADMSC implantation to discuss the safety and tolerability of the procedure.

\section{Materials and Methods}

This single-center, prospective, phase $1 / 2$ clinical safety study enrolled 8 patients with irreversible vision loss from AMD and SMD seen in the Retina and Vitreous Section of the Department of Ophthalmology at our University.
The study was performed in accordance with the Declaration of Helsinki and was approved by the Institutional Review Board (Review number for approval: 2014/390). It was also approved by the Review Board of Stem Cell Applications within the Ministry of Health in accordance with the regulations in our country (Review number for approval: 56733164/203). All patients were instructed about the objectives and methodology of the study and gave their written informed consent to participate.

\section{Patient eligibility}

There are limited data about clinical applications of MSCs and the safety of this therapy still needs to be clarified. Therefore, the study included patients with severe visual loss who are considered as legally blind.

Patients were included if they had: 1) A diagnosis of degenerative retinal disease classified clinically as dry $\mathrm{AMD}$ and SMD 2) Snellen best corrected visual acuity (BCVA) worse than 20/200 3) Visual field defects 4) Decreased multifocal electroretinography (mf ERG) recordings 5) Age older than 18 years.

Exclusion criteria were: 1) Previous ocular surgery other than cataract extraction 2) Presence of cataract or other media opacity that would prohibit high-quality ocular imaging or that would affect mfERG or visual field evaluation 3) Presence of other ophthalmic disease, such as glaucoma, uveitis, strabismus or nistagmus 4) Any other systemic diasease such as neurological disease that would affect the results. If both eyes were eligible for treatment, the eye with worse visual acuity was included in the study.

The demographic data of the patients were collected and ophthalmic evaluations and surgical procedures were performed by a single retina specialist (A.O). Fundus photography, fundus fluorescein angiography (FFA), optical coherence tomography (OCT), perimetry and mfERG recordings were performed by the same experienced ophthalmic technician.

All patients had a complete ophthalmic examination before surgery. BCVA was measured with Snellen chart and converted to $\log M a r$. All patients underwent fundus photography and FFA using the Zeiss FF 450 (Carl Zeiss Meditec AG, Germany). OCT was performed using the Heidelberg OCT Device (Heidelberg Engineering, Heidelberg, Germany) with a standardized scanning protocol. Visual field examination was performed by Octopus Goldmann Perimetry (Octopus 900, Haag Streit International, Switzerland). mfERG (Monpack 3, Metrovision, France) readings were recorded from each eye according to the International Society for Clinical Electrophysiology of Vision (ISCEV) guidelines (9). 


\section{Isolation and culture of ADMSCs}

For eliminating the donor based differences ADMSCs were obtained from the adipose tissue of a single donor for all patients in this study. Subcutaneous adipose tissue was carried to the laboratory in a transfer solution Dulbecco's Modified Eagle Medium (DMEM) with $1 \mathrm{~g} / 1$ D-Glucose (Low Glucose) (Biological Industries, Kibbutz Beit Haemek, Israel) containing $2 \%$ penicillin-streptomycin solution (10,000 units/ml Penicillin G Sodium Salt, $10 \mathrm{mg} / \mathrm{ml}$ Streptomycin Sulfate) (Biological Industries, Kibbutz Beit Haemek, Israel). Adipose tissue was washed in PBS (Biological Industries, Kibbutz Beit Haemek, Israel) three times and cut into small pieces and they were digested with $2,5 \mathrm{mg} / \mathrm{ml}$ collagenase type II (Sigma-Aldrich, Taufkirchen, Germany) for 30 minutes at $37^{\circ} \mathrm{C}$ to generate single-cell suspension. The digested tissues were filtered through a $70 \mu \mathrm{m}$ cell strainer and centrifuged at $350 \mathrm{~g}$ for 5 minutes to obtain a pellet. The pellet was resuspended in DMEM based media containing 10\% human serum, $1 \%$ Pen.-Step solution, and $1 \%$ stable glutamine (Biological Industries, Kibbutz Beit Haemek, Israel) and cultured at $37^{\circ} \mathrm{C}$ and $5 \% \mathrm{CO}_{2}$ incubator. After $3 \sim 4$ days of maintenance, the culture medium was removed to eliminate the non-attached cell fraction. The medium was replaced twice a week. The culture medium was changed after reaching $80 \sim 85 \%$ of confluence, and the cells were detached with $0.25 \%$ Trypsin EDTA Solution C (0.05\%), EDTA (0.02\%) (Biological Industries, Kibbutz Beit Haemek, Israel) collected, centrifuged at $350 \mathrm{~g}$ for 5 minutes and expanded to the required duplication. ADMSCs were then harvested and cryopreserved until use. Before the appointed surgery date, sufficient cryopreserved vials were thawed to provide the required dose for administration. The frozen ADMSCs were thawed and cultured in the same condition. ADMSCs were recovered, washed with PBS, and trypsin/EDTA and then resuspended in saline solution and third passage ADMSCs were transferred to the surgery room with the temperature controlled bag in one hour within $5 \mathrm{ml}$ vials. Total injection volume was $2.47 \times 10^{6} \pm 0,11 / 150 \mu 1$ per patient for this study. The procedure for ADMSCs preparation was performed under good manufacturing practices (GMP) conditions in Genome and Stem Cell Center of our University. All of the donation, manufacturing and testing procedures were carried out according to GMP protocols authorized by the Ministry of Health of our country. For release testing, ADMSCs were assessed for cell appearance, viability, identification, purity, content, and potency. In addition, ADMSCs were screened for contamination. Average cell viability for each treatment was over $90.0 \%$ and each patient received cell numbers between $2-3 \times 10^{6}$. Quality control analyses like mycoplasma analysis, endotoxin analysis were also completed.

For determining the potency; the suppresion effect of MSCs on lymphocytes was studied. Peripheral blood sample was taken from healthy donor and peripheral blood mononuclear cells were collected by density gradient centrifugation using Lymphocyte Separation Medium (LSM) (Biological Industries, BI, \#01-899-U04). Then PBMCs were incubated at $37^{\circ} \mathrm{C}$ in DMEM culture medium containing $10 \%$ human serum, $1 \%$ L-Glutamine and $1 \%$ penicillin/streptomycin. PBMCs were stimulated with $1 \%$ of Phytohemagglutinin (PHA-P, Sigma, \#L1668) and the effect of MSCs on lymphocyte proliferation was studied. $5 \times 10^{4}$ MSCs cultured with $5 \times 10^{5}$ PBMCs and after 48 hour cultivation, $0.5 \mathrm{mg} / \mathrm{ml}$ MTT was added. The entire medium was aspirated and $100 \mu 1 \mathrm{DMSO}$ was added to dissolve formazan crystals after 3 hours. Dissolved formazan crystals were read spectrophotometrically at 570 $\mathrm{nm}$. The percentage inhibition of lymphocytes proliferation was determined.

\section{Flow cytometry analyses}

ADMSCs were subjected to flow cytometry analyses for confirming that ADMSCs maintain their phenotypic characteristics in vitro. After the third passage, cells were harvested, centrifuged and resuspended in PBS at a minimum concentration of $1 \times 10^{6}$ cells $/ \mathrm{ml}$. Immunophenotyping characterization of ADMSCs was performed with antibodies against the following a combination of human antigens: CD11b, CD19, CD34, CD44, CD45, CD73, CD90, CD105 (BD Stem Flow hMSC kit, BD Cat. No: 562245). Flow cytometry analyses were performed by using Navios (Beckman Coulter, USA) before application for all patients in this study. The data were analyzed with KALUZA software (Beckman Coulter, USA).

Surgical technique: Surgeries were all carried out with local anesthesia. We performed a surgical technique defined as Limoli Retinal Restoration Technique (LRRT) which is described by Limoli et al (10). Each eye received a cell graft of ADMSCs between choroid and sclera.

The isolation and culture of ADMSCs and their flow cytometry analyses were performed as previously mentioned by our study group (11). For platelet rich plasma (PRP) preparation, $8 \mathrm{ml}$ of human peripheral blood was collected in a Regen-BCT tube (RegenKit; RegenLab, Le Mont-sur-Lausanne, $\mathrm{CH}$ ). The collected blood was centrifuged for $10^{\prime}$ at $1500 \mathrm{G}$.

The details of the surgery are as follows: The globe was deviated to the supero-nasal quadrant and conjunctiva was 
dissected at the infero-temporal quadrant at $8 \mathrm{~mm}$ from the limbus. A deep scleral flap of about $5 \times 5 \mathrm{~mm}$ was opened by radial hinge at the infero-temporal quadrant. The sclerectomy was deep enough to allow viewing of the color of the choroid. A flap from the orbital fat was extracted from a gap above the inferior oblique muscle. This tissue was laid on the scleral bed and sutured with $6 / 0$ vicryl at the proximal edge. The scleral flap was then sutured above the fat pedicle. The remaining space between the autologous fat graft, choroid, and scleral flaps was filled with $1 \mathrm{cc}$ of $2 \times 10^{6}$ ADMSCs and $1 \mathrm{cc}$ of PRP using a 25 -gauge cannula. The conjunctiva was sutured with $8 / 0$ vicryl.

Postoperative follow-up: Patients were hospitalized for one day after the surgery and received topical antibiotic and steroid drops four times daily during the first month. Immunosupressive agents were not administered considering that MSCs have an immunosuppressive function theirselves. Ophthalmic evaluations including BCVA, anterior and posterior segment examination, and OCT were performed at day 1 , at week 4 , at month 3 and 6 , and then 1 year after the surgery. Color fundus photographs, VF examination, FFA and mfERG recordings were also obtained before surgery and at month 1, 3, 6 and year 1 during the follow-up period.

\section{Results}

Morphology and phenotype of culture expanded hADMSC were presented in our previous report (11). Table 1 shows the demographic and clinical features of the 8 study patients who enrolled in this study. The age of the subjects ranged between 19 and 75 years. All subjects had advanced visual field loss in both eyes from degenerative macular diseases.

\section{Follow-up BCVA and eye examination}

All 8 patients completed one-year follow-up and none of them had systemic complications. There were no signs of intraocular inflammation in the study eyes on serial eye examinations. None of the patients had serious ocular complications due to the stem cell treatment. Seven of the 8 patients experienced visual acuity improvement and 1 patient remained stable during the first year. However when we evaluate the fellow eyes of the patients, we found that 7 of the 8 patients showed VA decrease during the follow-up and 1 patient remained stable (Table 1).

\section{Perimetry}

Seven subjects were noted to have improvement in visual field of the study eyes on Goldmann perimetry at 1-year follow-up examination. The remaining 1 study eye remained stable and all of the fellow eyes showed worsening

Table 1. Demographic details, clinical characteristics, visual acuity and visual field results of the treated eyes with stem cells and the untreated fellow eyes at baseline and at 1 year follow-up

\begin{tabular}{|c|c|c|c|c|c|c|}
\hline Subject No. & Age/sex/disease & Disease/study eye & $\begin{array}{c}\text { BCVA baseline } \\
\text { (logMAR) }\end{array}$ & $\begin{array}{c}\text { BCVA } 1 \text { year } \\
\text { (logMAR) }\end{array}$ & $\begin{array}{l}\text { MD (dB) } \\
\text { (Baseline) }\end{array}$ & $\begin{array}{c}M D(d B) \\
(1 \text { year })\end{array}$ \\
\hline \multirow[t]{2}{*}{1} & 19/F/SMD & OD (Fellow eye) & +0.60 & +0.70 & 15.5 & 23.7 \\
\hline & & OS (Study eye) & +1.3 & +1.0 & 23.1 & 21.7 \\
\hline \multirow[t]{2}{*}{2} & 24/M/SMD & OD (Study eye) & +1.3 & +1.3 & 12.0 & 9.6 \\
\hline & & OS (Fellow eye) & +1.3 & +1.6 & 13.3 & 14.7 \\
\hline \multirow[t]{2}{*}{3} & 20/M/SMD & OD (Study eye) & +2.0 & +1.5 & 28.1 & 28.6 \\
\hline & & OS (Fellow eye) & +1.6 & +2.0 & 27.7 & 28.5 \\
\hline \multirow[t]{2}{*}{4} & 31/F/SMD & OD (Fellow eye) & +1.5 & +1.6 & 18.9 & 21.9 \\
\hline & & OS (Study eye) & +1.5 & +1.0 & 21.6 & 19.1 \\
\hline \multirow[t]{2}{*}{5} & 75/MAMD & OD (Fellow eye) & +1.0 & +1.3 & 6.5 & 10.6 \\
\hline & & OS (Study eye) & +1.8 & +1.3 & 9.6 & 9.7 \\
\hline \multirow[t]{2}{*}{6} & 70/F/AMD & OD (Fellow eye) & +0.0 & +0.0 & 25.7 & 26.1 \\
\hline & & OS (Study eye) & +2.0 & +1.3 & 24.5 & 20.2 \\
\hline \multirow[t]{2}{*}{7} & 60/M/AMD & OD (Study eye) & +1.8 & +1.3 & 6.4 & 6.2 \\
\hline & & OS (Fellow eye) & +0.40 & +0.60 & 4.5 & 4.8 \\
\hline \multirow[t]{2}{*}{8} & 59/MAMD & OD (Study eye) & +2.0 & +1.3 & 18.5 & 17.9 \\
\hline & & OS (Fellow eye) & +0.70 & +1.0 & 7.3 & 8.6 \\
\hline
\end{tabular}

AMD: Age related macular degeneration, BCVA: Best corrected visual acuity, logMAR: Logarithm of the minimum angle of resolution units OD: Oculus dexter, OS: Oculus sinister, SMD: Stargardts' macular dystrophy, MD: Mean deviation dB: Decibel. The numbers written in italics belong to the patients who experienced decrease during the follow-up period. 
regarding to the perimetry (Table 1, Fig. 1 and 2).

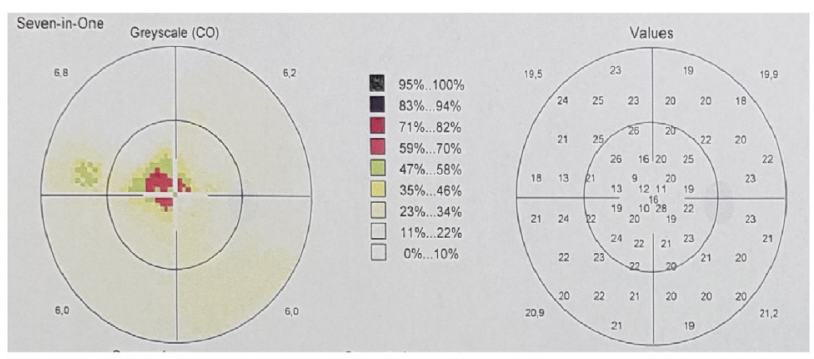

A

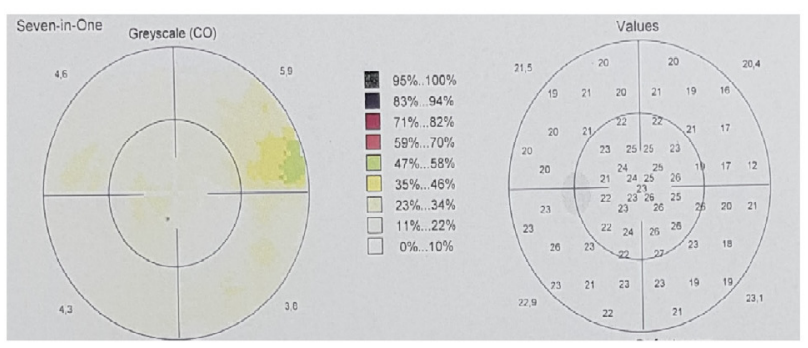

C

\section{Electroretinography}

All of the subjects had $\mathrm{mf}$ ERG recordings at baseline and at 12 months follow-up. There was an improvement

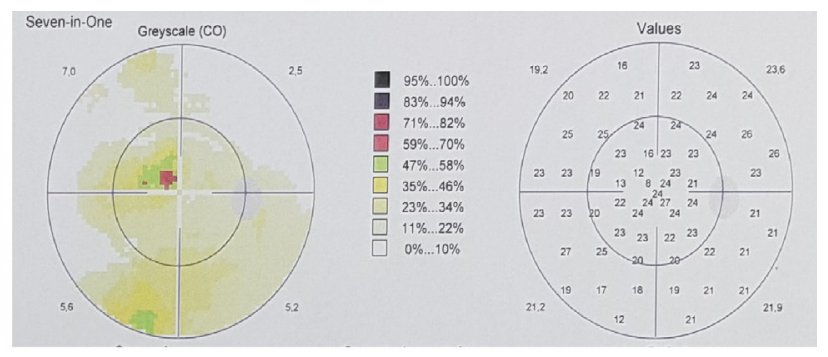

B

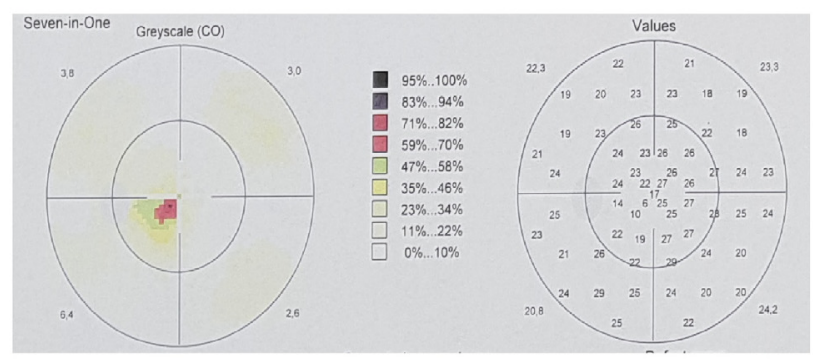

D

Fig. 1. Perimetry results of an $A M D$ subject before treatment $(A)$ and one year after treatment (B). Note that central visual field defect decreased during the first year period. Perimetry results of the fellow eye of the same subject during the study period $(C, D)$. Note the worsening of the central visual field defect.

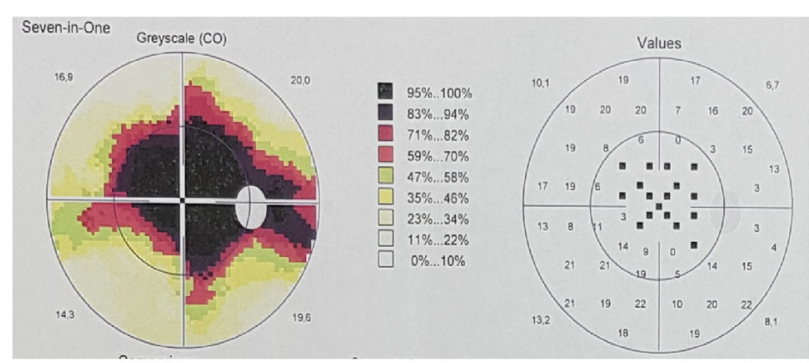

A

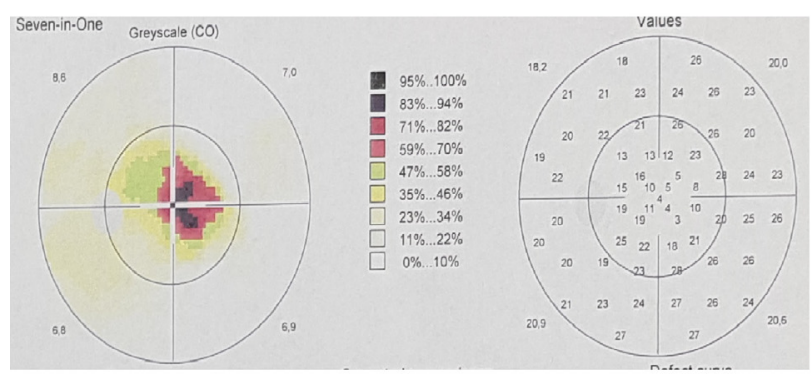

$\mathrm{C}$

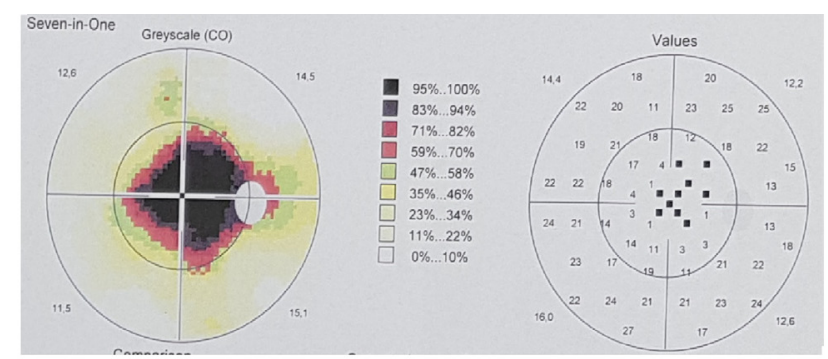

B

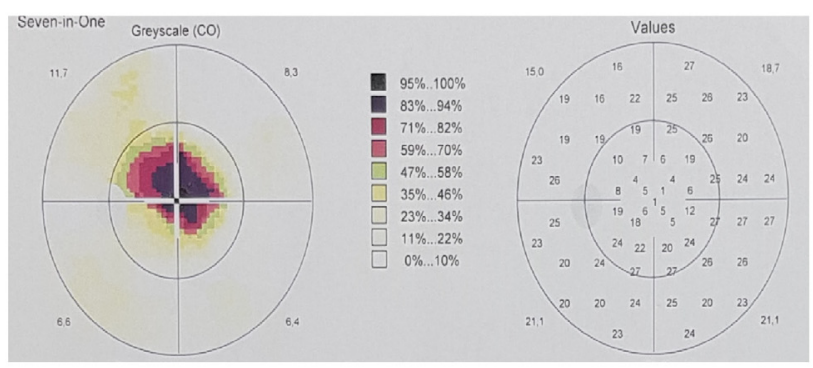

D

Fig. 2. Perimetry results of an SMD subject before treatment $(A)$ and one year after treatment (B). Note that central visual field defect decreased during the first year period. Perimetry results of the fellow eye of the same subject during the study period (C, $D$ ). Note the worsening of the central visual field defect. 
in the mf ERG amplitudes of the treated eyes at the end of the first year in all of the patients despite the worsening of the fellow eyes (Table 2, Fig. 3 and 4). The majority of implicit times of both eyes remained nearly the same after the treatment (Table 3).

\section{Fluorescein angiography}

All patients who underwent ADMSCs implantation revealed no signs of fluid collection, edema, persistent leak- age on FFA.

\section{OCT findings}

We found no morphological changes in OCT scans of the both eyes of the patients. Central macular thickness (CMT) measurements of the all treated eyes remained almost the same. CCT showed thickening in the half of the treated eyes. Both CMT and central choroidal thickness (CCT) measurements showed thinning of all fellow eyes

Table 2. Amplitudes of mfERGtests of the patients before and 1-year after treatment $\mathrm{mfERG}=$ multifocal electroretinography

\begin{tabular}{|c|c|c|c|c|}
\hline $\begin{array}{c}\text { mfERG parameters amplitude P1 } \\
\qquad\left(\mathrm{N} v / \mathrm{deg}^{2}\right)\end{array}$ & Baseline study eye & 1 Year study eye & Baseline fellow eye & 1 Year fellow eye \\
\hline \multicolumn{5}{|l|}{ Subject 1} \\
\hline Ring $1\left(<2^{\circ}\right)$ & 365.0 & 465.0 & 381.0 & 379.0 \\
\hline Ring $2\left(2 \sim 5^{\circ}\right)$ & 247.0 & 277.0 & 282.0 & 242.0 \\
\hline Ring $3\left(5 \sim 10^{\circ}\right)$ & 266.0 & 292.0 & 271.0 & 275.0 \\
\hline Ring $4\left(10 \sim 15^{\circ}\right)$ & 235.0 & 265.0 & 280.0 & 212.0 \\
\hline \multicolumn{5}{|l|}{ Subject 2} \\
\hline Ring $1\left(<2^{\circ}\right)$ & 326.0 & 382.0 & 330.0 & 306.0 \\
\hline Ring $2\left(2 \sim 5^{\circ}\right)$ & 248.0 & 267.0 & 232.0 & 220.0 \\
\hline Ring $3\left(5 \sim 10^{\circ}\right)$ & 101.0 & 309.0 & 123.0 & 122.0 \\
\hline Ring $4\left(10 \sim 15^{\circ}\right)$ & 106.0 & 282.0 & 102.0 & 118.0 \\
\hline \multicolumn{5}{|l|}{ Subject 3} \\
\hline Ring $1\left(<2^{\circ}\right)$ & 147.0 & 257.0 & 236.0 & 159.0 \\
\hline Ring $2\left(2 \sim 5^{\circ}\right)$ & 156.0 & 287.0 & 259.0 & 231.0 \\
\hline Ring $3\left(5 \sim 10^{\circ}\right)$ & 167.0 & 221.0 & 197.0 & 114.0 \\
\hline Ring $4\left(10 \sim 15^{\circ}\right)$ & 163.0 & 250.0 & 159.0 & 160.0 \\
\hline \multicolumn{5}{|l|}{ Subject 4} \\
\hline Ring $1\left(<2^{\circ}\right)$ & 364.0 & 387.0 & 389.0 & 184.0 \\
\hline Ring $2\left(2 \sim 5^{\circ}\right)$ & 357.0 & 404.0 & 336.0 & 329.0 \\
\hline Ring $3\left(5 \sim 10^{\circ}\right)$ & 398.0 & 502.0 & 517.0 & 521.0 \\
\hline Ring $4\left(10 \sim 15^{\circ}\right)$ & 551.0 & 607.0 & 555.0 & 662.0 \\
\hline \multicolumn{5}{|l|}{ Subject 5} \\
\hline Ring $1\left(<2^{\circ}\right)$ & 344.0 & 377.0 & 367.0 & 281.0 \\
\hline Ring $2\left(2 \sim 5^{\circ}\right)$ & 367.0 & 414.0 & 352.0 & 341.0 \\
\hline Ring $3\left(5 \sim 10^{\circ}\right)$ & 498.0 & 522.0 & 489.0 & 481.0 \\
\hline Ring $4\left(10 \sim 15^{\circ}\right)$ & 592.0 & 618.0 & 594.0 & 582.0 \\
\hline \multicolumn{5}{|l|}{ Subject 6} \\
\hline Ring $1\left(<2^{\circ}\right)$ & 118.0 & 236.0 & 595.0 & 590.0 \\
\hline Ring $2\left(2 \sim 5^{\circ}\right)$ & 183.0 & 253.0 & 201.0 & 209.0 \\
\hline Ring $3\left(5 \sim 10^{\circ}\right)$ & 186.0 & 308.0 & 231.0 & 214.0 \\
\hline Ring $4\left(10 \sim 15^{\circ}\right)$ & 458.0 & 468.0 & 262.0 & 290.0 \\
\hline \multicolumn{5}{|l|}{ Subject 7} \\
\hline Ring $1\left(<2^{\circ}\right)$ & 903.0 & 912.0 & 827.0 & 567.0 \\
\hline Ring $2\left(2 \sim 5^{\circ}\right)$ & 765.0 & 893.0 & 679.0 & 466.0 \\
\hline Ring $3\left(5 \sim 10^{\circ}\right)$ & 826.0 & 994.0 & 963.0 & 821.0 \\
\hline Ring $4\left(10 \sim 15^{\circ}\right)$ & 1132.0 & 1136.0 & 1125.0 & 958.0 \\
\hline \multicolumn{5}{|l|}{ Subject 8} \\
\hline Ring $1\left(<2^{\circ}\right)$ & 304.0 & 430.0 & 1105.0 & 1008.0 \\
\hline Ring $2\left(2 \sim 5^{\circ}\right)$ & 512.0 & 607.0 & 780.0 & 705.0 \\
\hline Ring $3\left(5 \sim 10^{\circ}\right)$ & 821.0 & 870.0 & 1063.0 & 952.0 \\
\hline Ring $4\left(10 \sim 15^{\circ}\right)$ & 1121.0 & 1231.0 & 1184.0 & 1071.0 \\
\hline
\end{tabular}




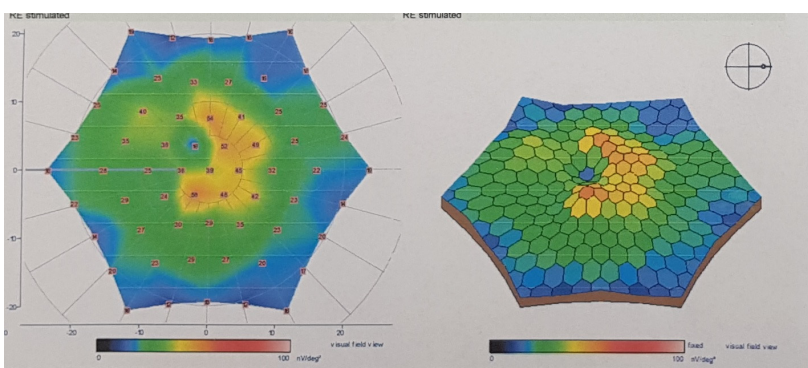

A

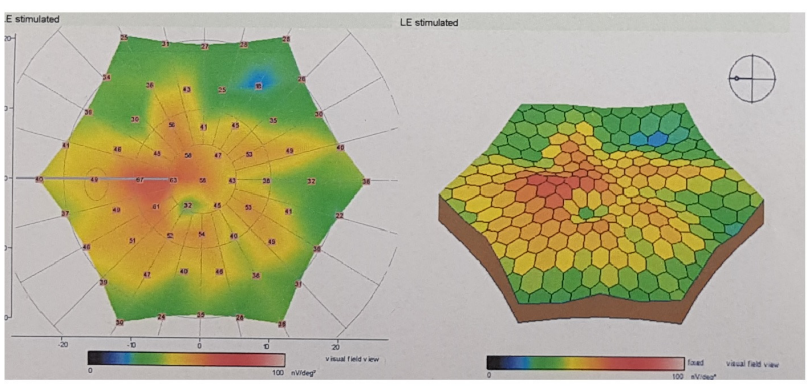

C

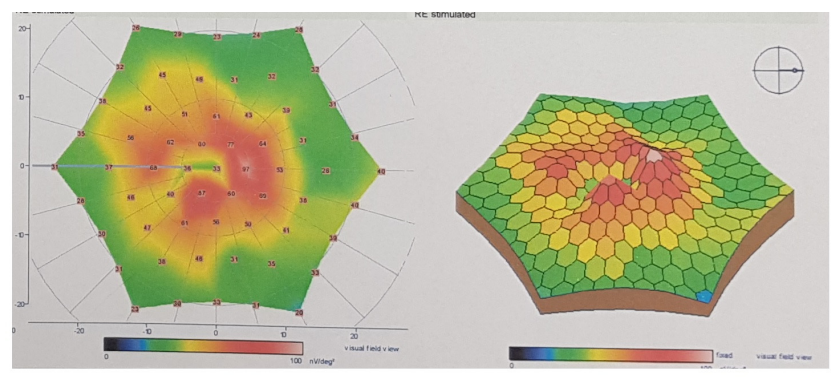

B

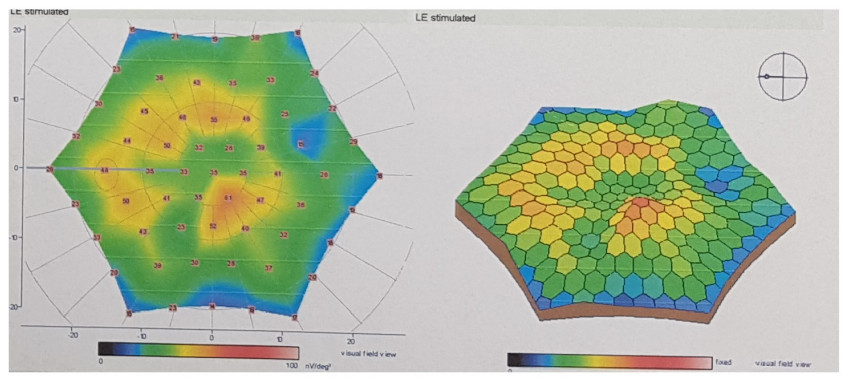

D

Fig. 3. mfERG recording of the same AMD subject before treatment (A) and one year after treatment (B). Note the improvements in mfERG recordings especially in the central rings shown with the color maps and $3 \mathrm{D}$ visualization maps. mfERG recordings of the fellow eye showed worsening in the central areas (C, D).
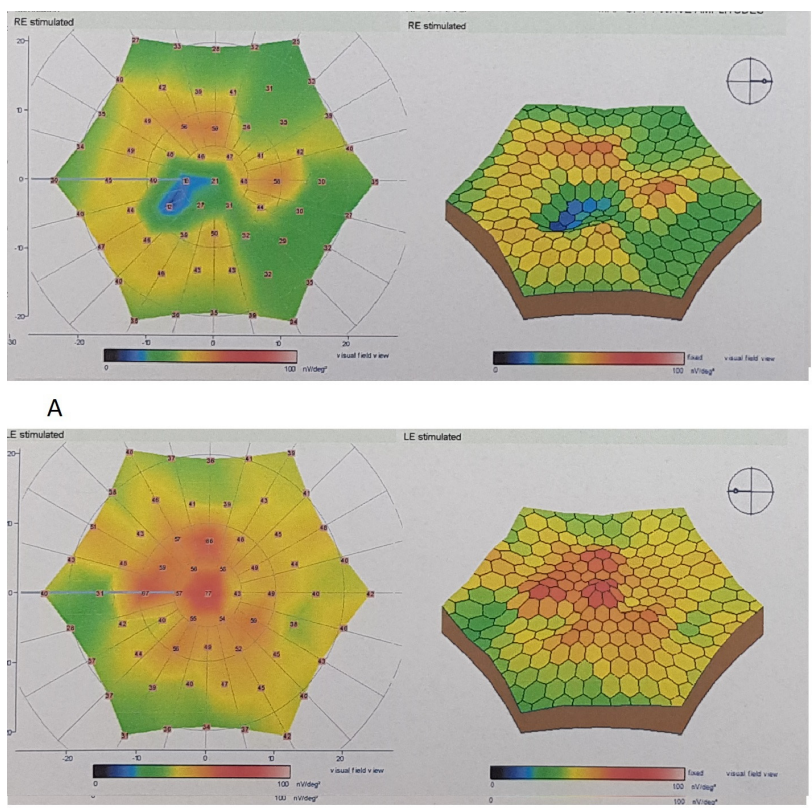

C

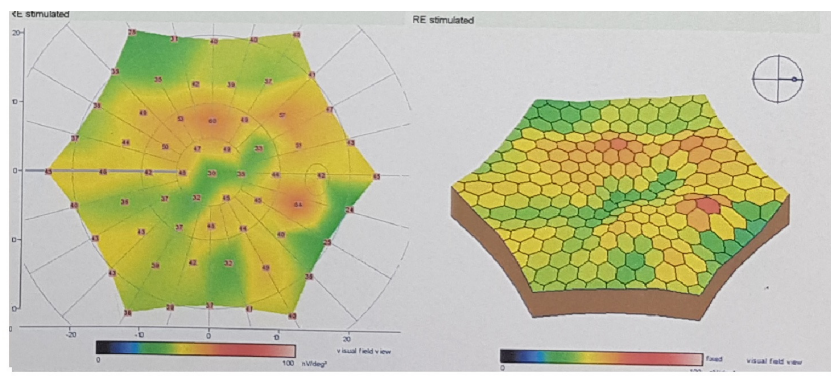

B

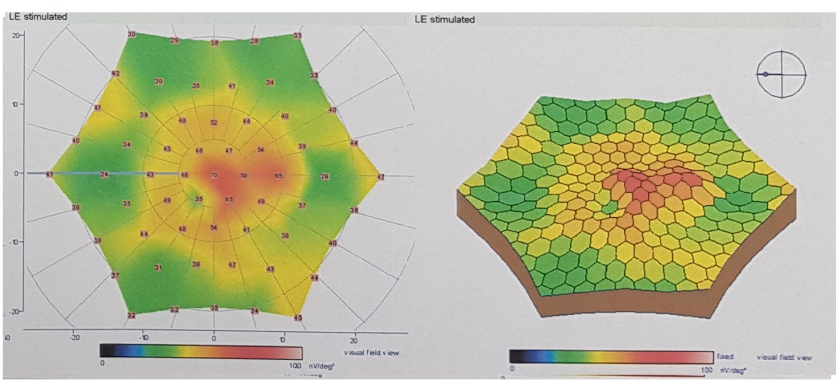

D

Fig. 4. mfERG recording of the same SMD subject before treatment (A) and one year after treatment (B). Note the improvements in mfERG recordings especially in the central rings shown with the color maps and 3D visualization maps. mfERG recordings of the fellow eye showed worsening in the central areas (C, D). 
Table 3. Implicit times of mfERG tests of the patients before and 1-year after treatment $\mathrm{mfERG}=$ multifocal electroretinography

\begin{tabular}{|c|c|c|c|c|}
\hline mfERG parameters implicit time P1 (ms) & Baseline study eye & 1 Year study eye & Baseline fellow eye & 1 Year fellow eye \\
\hline \multicolumn{5}{|l|}{ Subject 1} \\
\hline Ring $1\left(<2^{\circ}\right)$ & 53.5 & 51.5 & 53.2 & 52.7 \\
\hline Ring $2\left(2 \sim 5^{\circ}\right)$ & 54.2 & 52.1 & 53.6 & 52.9 \\
\hline Ring $3\left(5 \sim 10^{\circ}\right)$ & 51.6 & 53.5 & 56.4 & 56.3 \\
\hline Ring $4\left(10 \sim 15^{\circ}\right)$ & 55.0 & 55.3 & 56.3 & 58.0 \\
\hline \multicolumn{5}{|l|}{ Subject 2} \\
\hline Ring $1\left(<2^{\circ}\right)$ & 50.5 & 49.3 & 44.4 & 45.1 \\
\hline Ring $2\left(2 \sim 5^{\circ}\right)$ & 55.7 & 48.2 & 49.4 & 56.2 \\
\hline Ring $3\left(5 \sim 10^{\circ}\right)$ & 58.3 & 51.7 & 54.6 & 58.0 \\
\hline Ring $4\left(10 \sim 15^{\circ}\right)$ & 59.9 & 59.6 & 51.6 & 57.0 \\
\hline \multicolumn{5}{|l|}{ Subject 3} \\
\hline Ring $1\left(<2^{\circ}\right)$ & 47.7 & 44.1 & 47.8 & 45.6 \\
\hline Ring $2\left(2 \sim 5^{\circ}\right)$ & 46.8 & 48.8 & 51.6 & 47.6 \\
\hline Ring $3\left(5 \sim 10^{\circ}\right)$ & 47.4 & 51.2 & 48.8 & 53.6 \\
\hline Ring $4\left(10 \sim 15^{\circ}\right)$ & 56.1 & 49.1 & 56.6 & 49.5 \\
\hline \multicolumn{5}{|l|}{ Subject 4} \\
\hline Ring $1\left(<2^{\circ}\right)$ & 46.4 & 45.7 & 47.4 & 46.4 \\
\hline Ring $2\left(2 \sim 5^{\circ}\right)$ & 44.3 & 43.7 & 46.0 & 46.2 \\
\hline Ring $3\left(5 \sim 10^{\circ}\right)$ & 43.6 & 43.8 & 44.8 & 44.1 \\
\hline Ring $4\left(10 \sim 15^{\circ}\right)$ & 45.5 & 44.7 & 45.6 & 46.3 \\
\hline \multicolumn{5}{|l|}{ Subject 5} \\
\hline Ring $1\left(<2^{\circ}\right)$ & 47.7 & 49.8 & 48.2 & 46.9 \\
\hline Ring $2\left(2 \sim 5^{\circ}\right)$ & 49.6 & 47.1 & 46.2 & 45.3 \\
\hline Ring $3\left(5 \sim 10^{\circ}\right)$ & 47.8 & 46.8 & 47.2 & 45.9 \\
\hline Ring $4\left(10 \sim 15^{\circ}\right)$ & 46.8 & 46.1 & 46.9 & 46.9 \\
\hline \multicolumn{5}{|l|}{ Subject 6} \\
\hline Ring $1\left(<2^{\circ}\right)$ & 47.0 & 53.3 & 53.5 & 53.3 \\
\hline Ring $2\left(2 \sim 5^{\circ}\right)$ & 50.9 & 47.1 & 50.9 & 49.1 \\
\hline Ring $3\left(5 \sim 10^{\circ}\right)$ & 48.0 & 48.2 & 46.1 & 48.2 \\
\hline Ring $4\left(10 \sim 15^{\circ}\right)$ & 47.1 & 49.0 & 47.1 & 47.8 \\
\hline \multicolumn{5}{|l|}{ Subject 7} \\
\hline Ring $1\left(<2^{\circ}\right)$ & 51.4 & 52.9 & 50.9 & 54.5 \\
\hline Ring $2\left(2 \sim 5^{\circ}\right)$ & 49.0 & 49.1 & 47.8 & 53.6 \\
\hline Ring $3\left(5 \sim 10^{\circ}\right)$ & 47.7 & 47.6 & 46.9 & 50.5 \\
\hline Ring $4\left(10 \sim 15^{\circ}\right)$ & 46.8 & 46.7 & 45.1 & 49.2 \\
\hline \multicolumn{5}{|l|}{ Subject 8} \\
\hline Ring $1\left(<2^{\circ}\right)$ & 45.4 & 43.8 & 48.8 & 46.1 \\
\hline Ring $2\left(2 \sim 5^{\circ}\right)$ & 43.2 & 42.7 & 45.0 & 44.2 \\
\hline Ring $3\left(5 \sim 10^{\circ}\right)$ & 43.6 & 43.0 & 43.9 & 43.1 \\
\hline Ring $4\left(10 \sim 15^{\circ}\right)$ & 43.5 & 43.1 & 43.6 & 43.3 \\
\hline
\end{tabular}

(Table 4).

\section{Discussion}

The majority of the eyes in the study group showed improvement in VA and perimetry, and all of the study eyes showed improvement in electrophysiological results with no ocular and systemic complications; whereas the majority of fellow eyes of the patients showed decrease in VA, perimetric and eletrophysiological results. The improve- ment of the VA of the study group was consistent through 1 year follow-up. The improvement in visual acuity was correlated with mfERG and VF results. The improvement in these functional and structural testings were continuous through 1 year. No serious complications occurred during the follow-up period.

Low vision is known to deteriorate daily life, and chronic visual impairment caused by retinal diseases has been shown to have effect on quality of life scales (12). Degenerative retinal diseases have no curative treatment 
Table 4. OCT measurements of the treated and the fellow eyes (values in $\mu \mathrm{m}$ )

\begin{tabular}{|c|c|c|c|c|c|}
\hline Subject No. & & Baseline of the study eye & 1 Year study eye & Baseline fellow eye & 1 Year fellow eye \\
\hline \multirow[t]{2}{*}{1} & CMT & 81 & 78 & 109 & 87 \\
\hline & CCT & 235 & 257 & 374 & 248 \\
\hline \multirow{2}{*}{2} & CMT & 100 & 83 & 105 & 78 \\
\hline & СCT & 266 & 237 & 269 & 227 \\
\hline \multirow{2}{*}{3} & CMT & 163 & 171 & 185 & 138 \\
\hline & CCT & 203 & 199 & 242 & 180 \\
\hline \multirow{2}{*}{4} & CMT & 74 & 70 & 85 & 83 \\
\hline & CCT & 286 & 290 & 313 & 220 \\
\hline \multirow{2}{*}{5} & CMT & 131 & 137 & 190 & 131 \\
\hline & ССТ & 195 & 242 & 238 & 227 \\
\hline \multirow{2}{*}{6} & CMT & 20 & 19 & 17 & 15 \\
\hline & CCT & 128 & 122 & 130 & 105 \\
\hline \multirow{2}{*}{7} & CMT & 23 & 27 & 90 & 83 \\
\hline & ССТ & 190 & 183 & 322 & 302 \\
\hline \multirow[t]{2}{*}{8} & CMT & 104 & 98 & 124 & 98 \\
\hline & СCT & 330 & 219 & 424 & 384 \\
\hline
\end{tabular}

CMT: Central macular thickness; CCT: Central choroidal thickness.

The numbers written in italics belong to the patients who experienced decrease during the follow-up period. The numbers written in bold represent the patients who had increase in CCT.

to date, however many options are being investigated including retinal prosthetic devices, gene therapies and cell therapies. Stem cell based treatment modalities are rising in trend for "irreversible" neuropathies and retinopathies in various specialties. These treatment options are giving hope for reversing the cell death or damage; or at least causing the functional enhancement of the remaining viable cells through gene expression changes and antiapoptotic effect. It has been used recently in various ophthalmic diseases which mainly includes hereditary/age related retinal disorders and optic neuropathies and has been shown to have promising results. Various ways of application routes and biological materials have been proposed up-to date. Our study group has also performed and published the results of subretinal delivery method with ADMSCs $(11,13)$. With these method complications requiring seconds surgeries have occurred during follow-up such as epiretinal membrane formation at the implantation site and peripheral tractional detachment and subretinal delivery technique was abandoned and was replaced with suprachoroidal delivery method. This method has been first introduced by Limoli and his colleagues and was proven safe with no complications $(10,14)$. In our study we did not observe any complication other than only a subconjunctival hemorrhage that usually absorbs in a few days. Suprachoroidal delivery method being near the choroid also has the advantage of allowing the produced GFs to enter the choroidal flow and reaching the endothelial cell receptors and eventually reaching to and interacting with RPEs, Muller cells and photoreceptors and managing to consant GF secretion in the choroidal flow (15). Interaction with the retinal cells also trigger an intracellular pathway. The continuous improvement in our study through 1-year follow-up can relate to this phenomenan. The choroidal thickening in the set of our patients can be the reflectance of increase in choroidal perfusion compatible with previous study results (16). Preclinical data with vascular endothelial growth factor inhibitors and triamcinolone acetonide have shown that suprachoroidal injection results in more posterior distribution of the agents and lesser exposure to the anterior segment compared to intravitreal administration (17). Because of its anterior limitation by scleral spur, the flow from the suprachoroidal space directs towards posterior pole. To conclude suprachoroidal delivery seems to have an improved risk/ benefit ratio when compared to subretinal delivery approaches.

ADMSCs are known to be a rich source of growth factors (GF), which are proteins that are known to have role in halting or slowing the apoptosis process, and have been studied for their role in treatment of retinal atrophy (18). Both PRP and ADMSCs are the sources of autologous GFs used in our study. In various studies delayed apoptosis and paracrine secretion of retinal cells have been demonstrated via surgically grafted adipose tissue in the suprachoroidal space (19-21). Recent published data have shown 
that IPSC sheets as a monolayer used for tissue replacement therapy in AMD, could represent gene expression patterns similar to those of native RPE with expression of RPE markers and exhibition of polarized GF secretion and phagocytotic ability $(21,22)$ Whichever the source is the main objective in cell therapies is to slow down or prevent the death of photoreceptors. Various sources of stem cells including ESCs, IPSCs and MSCs have been investigated which are all capable of self-renewal and show multipotency. Peripheral blood, umblical cord, bone marrow and adipose tissue are the sources of MSCs. MSCs have the advantage of immunosuppressant function and the inhibition of the release of proinflammatory cytokines which also allows for both autologous and allogeneic transplantation, hence do not require immunosupression.

Because this is a phase $1 / 2$ study and the main objective is to report the safety results, the main limitation of this is study is the severe visual field defects and severe visual loss of the included patients. It is known that stem cell based therapies work better when there is more viable tissue and so with patients having more residual visual capacity. It is shown that retinal thickness average (RTA) measurements serve as a diagnostic criterion for stem cell application treatments and better outcomes are revealed in dry type AMD patients with RTA measurements of 250 $\mu \mathrm{m}$ and greater which also correlate with electroretinography (ERG) responses (23). The neuroenhancement which is improved by GFs is proportional to the areas present of greater cellularity which also corresponds with electrophysiology. In a very recent study including patients with retinitis pigmentosa, Limoli et al. (24) also found that the group with a foveal thickness greater than $190 \mu \mathrm{m}$ is associated with a better prognosis. Considering the late stage spectrum of the patients in our study the GF and receptor interaction would be poor and therefore could not represent the potential response that would be received from the patients in early-moderate stages of the disease. Even with this fact the results of our study, despite the heterogeneity of the recruited subjects is promising with no serious complications and gives hope for studies of patients with the beginning/medium phase of their disease.

In conclusion, stem cell treatment with suprachoroidal implantation of ADMSCs seems to be safe and effective. The results of our study provide the first evidence of the medium-term safety of suprachoroidal implantation of ADMSCs in human which would be beneficial for future studies and merits further investigation. To optimize the interventional timing, site of graft replacement and delivery system future studies including larger number of cases with better visual acuities will be necessary.

\section{Acknowledgments}

This study is funded by The Scientific Research Support Division of Erciyes University.

\section{Potential Conflict of Interest}

The authors have no conflicting financial interest.

\section{Author Contributions}

AO: Study design, patient selection and follow-up, surgical intervention, data collection, manuscript preparation

ZBG: Study design, preparation of stem cells, laboratory tests, manuscript preparation

DGS: Data collection, manuscript preparation

NSK: Patient follow-up, data collection, manuscript preparation

All authors read and approved the manuscript.

\section{References}

1. Öner A. Stem cell treatment in retinal diseases: recent developments. Turk J Ophthalmol 2018;48:33-38

2. Kahraman NS, Öner A. Stem cell treatment in degenerative retinal and optic nerve diseases. Trak Univ J Nat Sci 2019; 20:11-16

3. Mead B, Berry M, Logan A, Scott RA, Leadbeater W, Scheven BA. Stem cell treatment of degenerative eye disease. Stem Cell Res 2015;14:243-257

4. Kalbermatten DF, Schaakxs D, Kingham PJ, Wiberg M. Neurotrophic activity of human adipose stem cells isolated from deep and superficial layers of abdominal fat. Cell Tissue Res 2011;344:251-260

5. Mead B, Logan A, Berry M, Leadbeater W, Scheven BA. Paracrine-mediated neuroprotection and neuritogenesis of axotomised retinal ganglion cells by human dental pulp stem cells: comparison with human bone marrow and adipose-derived mesenchymal stem cells. PLoS One 2014;9: e109305

6. Tang Z, Zhang Y, Wang Y, Zhang D, Shen B, Luo M, Gu P. Progress of stem/progenitor cell-based therapy for retinal degeneration. J Transl Med 2017;15:99

7. Khan M, Agarwal K, Loutfi M, Kamal A. Present and possible therapies for age-related macular degeneration. ISRN Ophthalmol 2014;2014:608390

8. Fujinami K, Lois N, Davidson AE, Mackay DS, Hogg CR, Stone EM, Tsunoda K, Tsubota K, Bunce C, Robson AG, Moore AT, Webster AR, Holder GE, Michaelides M. A longitudinal study of stargardt disease: clinical and electrophysiologic assessment, progression, and genotype correlations. Am J Ophthalmol 2013;155:1075-1088.e13

9. Hood DC, Bach M, Brigell M, Keating D, Kondo M, Lyons JS, Marmor MF, McCulloch DL, Palmowski-Wolfe AM. ISCEV standard for clinical multifocal electroretinography 
(mfERG) (2011 edition). Doc Ophthalmol 2012;124:1-13

10. Limoli PG, Vingolo EM, Morales MU, Nebbioso M, Limoli C. Preliminary study on electrophysiological changes after cellular autograft in age-related macular degeneration. Medicine (Baltimore) 2014;93:e355

11. Oner A, Gonen ZB, Sinim N, Cetin M, Ozkul Y. Subretinal adipose tissue-derived mesenchymal stem cell implantation in advanced stage retinitis pigmentosa: a phase I clinical safety study. Stem Cell Res Ther 2016;7:178

12. Kahraman NS, Sevim DG, Öner A. Cross-validation of the Turkish version of the 28-item impact of vision impairment profile test. Open J Ophthalmol 2019;9:194-202

13. Oner A, Gonen ZB, Sevim DG, Sinim N, Cetin M, Ozkul Y. First-year results of subretinal mesenchymal stem cell implantation in severe retinitis pigmentosa. J Stem Cell Res Ther 2019;9:454

14. Limoli PG, Vingolo EM, Limoli C, Scalinci SZ, Nebbioso $M$. Regenerative therapy by suprachoroidal cell autograft in dry age-related macular degeneration: preliminary in vivo report. J Vis Exp 2018;(132):56469

15. Habot-Wilner Z, Noronha G, Wykoff CC. Suprachoroidally injected pharmacological agents for the treatment of chorio-retinal diseases: a targeted approach. Acta Ophthalmol 2019;97:460-472

16. Oner A, Gonen ZB, Sevim DG, Smim Kahraman N, Unlu M. Suprachoroidal adipose tissue-derived mesenchymal stem cell implantation in patients with dry-type age-related macular degeneration and Stargardt's macular dystrophy: 6-month follow-up results of a phase 2 study. Cell
Reprogram 2018;20:329-336

17. Thanos C, Emerich D. Delivery of neurotrophic factors and therapeutic proteins for retinal diseases. Expert Opin Biol Ther 2005;5:1443-1452

18. Schäffler A, Büchler C. Concise review: adipose tissue-derived stromal cells--basic and clinical implications for novel cell-based therapies. Stem Cells 2007;25:818-827

19. Tischler M. Platelet rich plasma. The use of autologous growth factors to enhance bone and soft tissue grafts. N Y State Dent J 2002;68:22-24

20. Kahraman NS, Oner A. Subtenon injection of autologous platelet-rich plasma in retinitis pigmentosa: is it a new therapeutic option? Open J Ophthalmol 2020;10:77-88

21. Kamao H, Mandai M, Okamoto S, Sakai N, Suga A, Sugita S, Kiryu J, Takahashi M. Characterization of human induced pluripotent stem cell-derived retinal pigment epithelium cell sheets aiming for clinical application. Stem Cell Reports 2014;2:205-218

22. Dang Y, Zhang C, Zhu Y. Stem cell therapies for age-related macular degeneration: the past, present, and future. Clin Interv Aging 2015;10:255-264

23. Limoli PG, Limoli C, Vingolo EM, Scalinci SZ, Nebbioso $M$. Cell surgery and growth factors in dry age-related macular degeneration: visual prognosis and morphological study. Oncotarget 2016;7:46913-46923

24. Limoli PG, Vingolo EM, Limoli C, Nebbioso M. Stem cell surgery and growth factors in retinitis pigmentosa patients: pilot study after literature review. Biomedicines 2019;7:94 